\title{
Perencanaan Lanskap untuk Pengembangan Wisata di Gunung Padang, Kota Padang, Sumatera Barat
}

\author{
Ulfa Khairani $1^{1^{*}}$, Lury Sevita Yusiana ${ }^{1}$, Ni Nyoman Ari Mayadewi ${ }^{2 \star}$
}

1. Prodi Arsitektur Lanskap, Fakultas Pertanian, Universitas Udayana, Indonesia 80236

2. Prodi Agroekoteknologi, Fakultas Pertanian, Universitas Udayana, Indonesia 80236

*E-mail: lury.yusiana@unud.ac.id

\begin{abstract}
Landscape Planning for Tourism Development in Gunung Padang, Padang City, West Sumatra. Gunung Padang is one of the tourist attractions located in the city of Padang, this area is surrounded by vegetation and animals that live well, so this tourist attraction is included in the protected and preserved tourist areas. It has tourism potential such as tourist attractions, tourist activities, and tourism supporting facilities. Various tourism potentials have not been developed as a whole by the management. Based on this, it is necessary to optimize and provide recommendations in order to be developed. The purpose of this research is to develop landscape planning to support tourism development in Gunung Padang, Padang City, through the stages of preparation, inventory, analysis, synthesis, and planning aimed at sustainable tourism development. Analysis and synthesis are carried out to produce basic concepts and concepts of tourism development. The final product of this research is the planned tourism development site in Gunung Padang. The division of space is based on the needs and according to the conditions owned by the tourist area in order to support security and comfort in travel activities. The final result of this research is a map of the plan of attractions and tourist activities, as well as a map of the layout plan of tourist facilities in Gunung Padang.
\end{abstract}

Keywords: Attractions, tourist activities, tourist facilities, tourism development plans

\section{Pendahuluan}

Sumatera Barat merupakan daerah yang kaya dengan panorama alamnya, terletak di pesisir barat bagian tengah Pulau Sumatera, yang terdiri dari dataran rendah di pantai barat dan dataran tinggi yang dikelilingi oleh Bukit Barisan. Kondisi alam yang terbentuk secara alami ini memiliki potensi wisata yang menarik apabila dikelola dengan baik, sehingga dapat menjadi daerah tujuan wisata yang potensial. Gunung Padang merupakan salah satu kawasan wisata yang berada di Kota Padang. Kawasan ini dikelola oleh Dinas Pariwisata dan Kebudayaan Kota Padang. Gunung Padang memiliki potensi wisata terdiri dari atraksi wisata yang berupa keindahan alam, peninggalan sejarah zaman kolonial Jepang yang berupa bunker, sebuah makam yang diyakini sebagai makam Siti Nurbaya, taman Siti Nurbaya, dan ikon Kota Padang yang berupa tagline "Padang Kota Tercinta". Terdapat aktivitas pengunjung seperti memancing, olahraga panjat tebing, menikmati pemandangan, piknik, hiking, dan kegiatan organisasi seperti bakti sosial. Selain itu, juga terdapat sarana dan prasarana penunjang wisata, serta keanekaragaman hayati flora dan fauna dari berbagai tipe perwakilan ekosistem pantai serta ekosistem hutan dataran rendah (Lerissa, 2014).

Berdasarkan hasil dari observasi, wawancara, dan studi pustaka, keberadaan wisata Gunung Padang saat ini belum dikelola secara maksimal, karena terdapat kendala dalam pengembangan wisata terutama dari pihak pengelola masih kurang mengkoordinasi kawasan wisata sehingga menyebabkan masih kurang optimalnya pengembangan wisata Gunung Padang, sisi anggaran dan kurangnya kesadaran masyarakat sekitar yang berperan dan bertanggung jawab atas pengelolaan kawasan wisata. Adanya permasalahan ini, maka perlu dilakukan sebuah penelitian tentang perencanaan lanskap untuk pengembangan wisata dengan menghadirkan potensi atraksi wisata, aktivitas wisata dan rekomendasi fasilitas wisata yang memberi keamanan dan kenyamanan bagi wisatawan. Penelitian ini dapat dijadikan sebagai acuan jika nantinya akan dilakukan pengembangan wisata oleh pengelola. 


\section{Metode}

\subsection{Lokasi dan Waktu Penelitian}

Penelitian berada di kawasan Gunung Padang, Sumatera Barat yang berlokasi di jalan Kampung Batu, muara Batang Arau, Kecamatan Padang Selatan, Kota Padang, Sumatera Barat, terlihat pada Gambar 1. Menurut hasil pencitraan lanskap, luas kawasan Gunung Padang yaitu $21,11 \mathrm{Ha}$, sebagian wilayah Gunung Padang dijadikan tempat wisata dengan luas kawasan 4,11 Ha (Lerissa, 2014). Gunung Padang merupakan sebuah bukit dengan ketinggian puncak \pm 400 mdpl dan memiliki luas puncak sekitar $260 \mathrm{~m}^{2}$ serta panjang jalur wisata $\pm 1,5 \mathrm{~km}$. Penelitian ini berlangsung selama 16 bulan mulai dari bulan Oktober 2018 sampai dengan bulan Januari 2020.

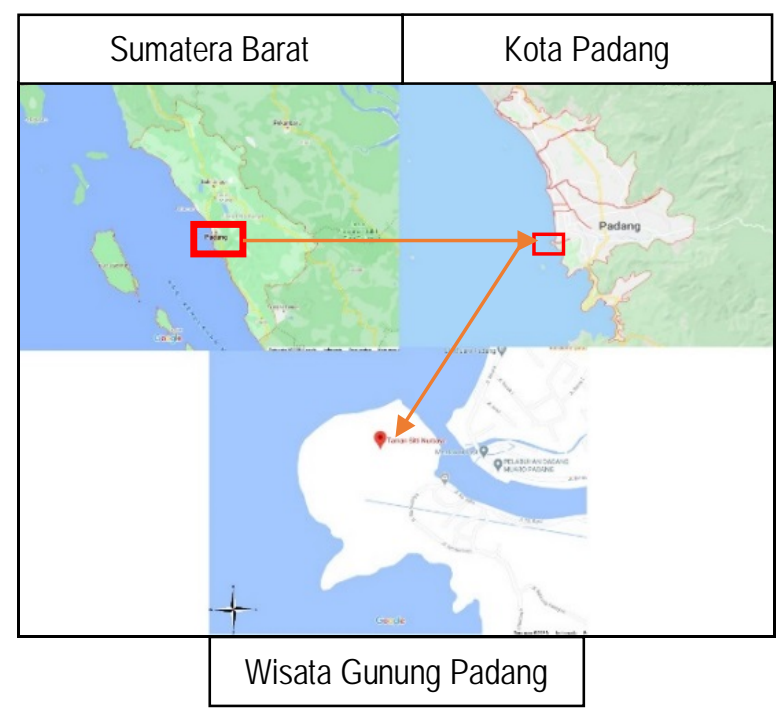

Gambar 1. Lokasi Penelitian Wisata Gunung Padang

(Sumber: Google Maps, 2019)

\subsection{Alat dan Bahan}

Alat dan bahan yang digunakan dalam pelaksanaan penelitian, yaitu alat tulis, meteran, handphone untuk mengambil gambar dan rekaman suara, laptop dengan perangkat lunak Microsoft Word, Microsoft Excel, Google Earth, Adobe Photoshop, ArcGIS. Bahan digunakan dalam penelitian ini adalah lembaran panduan wawancara.

\subsection{Metode Penelitian}

Metode yang digunakan dalam penelitian ini adalah metode survei yang dilakukan secara deskriptif kualitatif. Menggunakan tahapan penelitian perencanaan dan perancangan yang dikemukakan oleh Gold (1980), terdiri dari persiapan, inventarisasi, analisis, sintesis, konsep dan perencanaan. Teknik pengumpulan data dilakukan dengan cara observasi, wawancara dan studi pustaka. Informan dalam penelitian ini yaitu Dinas Pariwisata dan kebudayaan Kota Padang, masyarakat yang berperan dalam mengelola kawasan wisata, dan pengunjung wisata. Batasan penelitian ini terdapat pada jalur wisata Gunung Padang yang memiliki panjang jalur $\pm 1,5 \mathrm{Km}$. Penelitian ini difokuskan pada permasalahan potensi wisata, yang terdiri dari atraksi wisata, aktivitas wisata dan fasilitas wisata yang terdapat pada jalur wisata tersebut, sehingga menghasilkan perencanaan lanskap pengembangan wisata Gunung Padang. Produk akhir penelitian disajikan dalam bentuk gambar-gambar ilustrasi serta peta yang berupa peta atraksi, aktivitas wisata, dan peta tata fasilitas wisata.

\section{Hasil dan Pembahasan}

\subsection{Gambaran Umum Lokasi Penelitian}

Kawasan Gunung Padang secara geografis terletak pada titik 100020'55" BT dan 0057'55" LS dengan hamparan laut pesisir hingga pergunungan. Secara administratif termasuk dalam Kecamatan Padang Selatan, yang berada di arah barat Kota Padang tepatnya di muara Batang Arau, Kelurahan Batang 
Arau. Batasan daerah Gunung Padang pada bagaian sebelah barat berbatas dengan Samudra Hindia, sebelah timur berbatasan dengan permukiman dan Bungus Teluk Kabung, sebelah selatan Bungus Teluk Bayur dan Samudra Hindia, sebelah utara berbatasan dengan muara Batang Arau dan Kota Padang, terlihat pada Gambar 2.

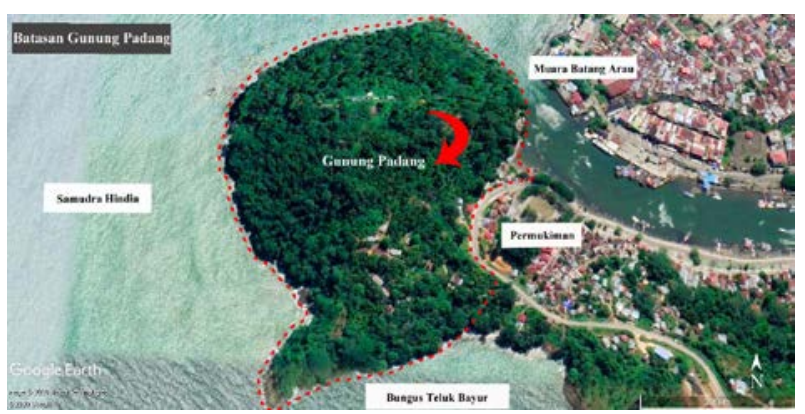

Gambar 2. Batasan Gunung Padang

(Sumber: Google Earth, 2020)

\subsection{Inventarisasi Tapak}

\subsubsection{Aspek Biofisik}

Perbukitan Gunung Padang memiliki topografi dengan kriteria kemiringan lereng yang bervariasi, mulai dari datar 0-13\%, landai-miring $14-25 \%$, curam $26-40 \%$ dan sangat curam $>40$. Luas lahan di kawasan Gunung Padang banyak ditumbuhi rumput hijau dan tumbuh-tumbuhan, beberapa area lahan hijau masih belum dimanfaatkan potensinya dikarenakan lahan tersebut berada di kawasan konservasi (Pratiwi, 2010).

Vegetasi yang berada di kawasan wisata Gunung Padang dominan seperti pala (Myristica fragrans) dan cengkeh (Syzygium aromaticum) merupakan tumbuhan yang menjadi komoditi utama ekspor pada zaman kolonial belanda, sehingga banyak ditanam di kawasan Gunung Padang ini (Lerissa, 2014). Satwa yang dapat ditemukan di kawasan wisata Gunung Padang, seperti monyet ekor panjang (Macaca fascicularis), lutung simpai (Presbytis melalophos), biawak (Varanus salvator) yang banyak di temukan di pinggir muara.

\subsubsection{Potensi Daya Tarik Wisata Gunung Padang}

Potensi daya tarik wisata Gunung Padang terdiri dari peninggalan sejarah zaman kolonial Jepang, tebing, makam Siti Nurbaya, visual tapak, taman Siti Nurbaya, tagline "Padang Kota Tercinta". Berikut gambar peta letak daya tarik wisata Gunung Padang terlihat pada Gambar 3.

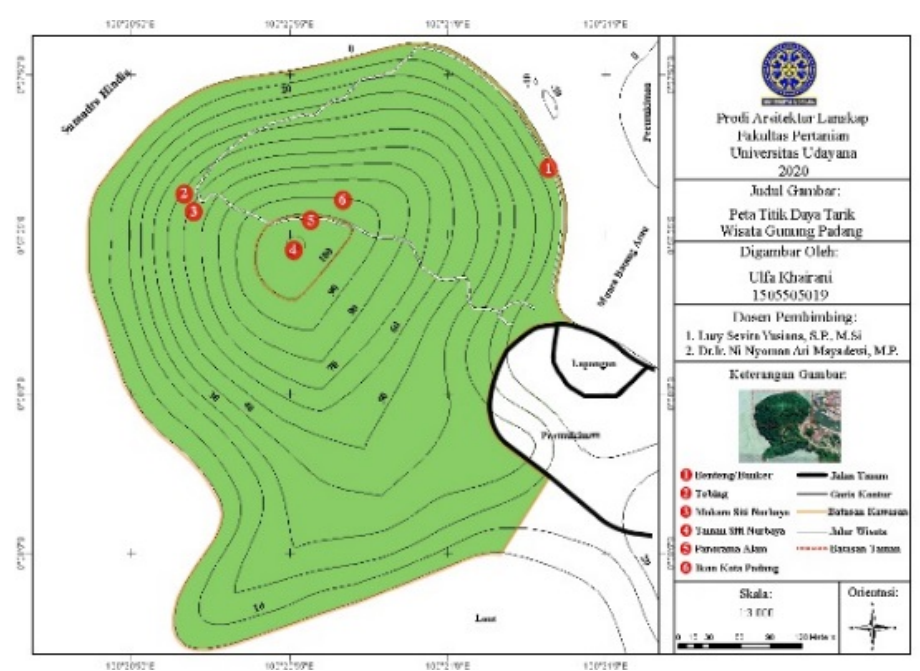

Gambar 3. Gambar Peta Potensi Daya Tarik Wisata Gunung Padang (Sumber: Hasil Pengolahan Data, 2020) 


\subsubsection{Fasilitas Wisata}

Wisata Gunung Padang memiliki sejumlah fasilitas wisata yaitu sarana dan prasarana penunjang wisata yang berfungsi untuk mengakomodasi kegiatan pariwisata bagi pengunjung. Berikut fasilitas yang telah tersedia di wisata Gunung Padang beserta kondisi saat ini berdasarkan hasil observasi lapangan yaitu, terlihat pada Tabel 1.

Tabel 1. Jenis Fasilitas, Potensi, Kendala Serta Jumlah Fasilitas yang Tersedia

\begin{tabular}{|c|c|c|c|}
\hline $\begin{array}{c}\text { Jenis } \\
\text { Fasilitas }\end{array}$ & Potensi & Kendala & $\begin{array}{c}\text { Jumlah } \\
\text { (Unit) }\end{array}$ \\
\hline Tempat parkir & Fasilitas parkir kendaraan pengunjung & Minimnya ketersediaan area parkir & 2 \\
\hline Pintu gerbang & $\begin{array}{l}\text { Area penerimaan, tiket masuk, pusat } \\
\text { informasi. }\end{array}$ & $\begin{array}{l}\text { Kurangnya papan informasi kawasan } \\
\text { wisata dan papan petunjuk arah }\end{array}$ & 1 \\
\hline Jalur wisata & Akses utama menuju daya tarik wisata & $\begin{array}{l}\text { Kondisi kurang terawat, akses jalur } \\
\text { wisata kurang aman digunakan oleh } \\
\text { pengunjung, Kurangnya ketersediaan } \\
\text { papan petunjuk arah, tempat sampah. }\end{array}$ & 3 \\
\hline Shelter & $\begin{array}{l}\text { Tempat istirahat, pemberhentian } \\
\text { pengunjung. }\end{array}$ & $\begin{array}{l}\text { Kurang terawat dan disalahgunakan } \\
\text { seperti dijadikan tempat berjualan yang } \\
\text { dilakukan oleh masyarakat sekitar }\end{array}$ & 5 \\
\hline Batu refleksi & $\begin{array}{l}\text { Tempat sarana olahraga dan sarana } \\
\text { kesehatan. }\end{array}$ & $\begin{array}{l}\text { Area terbatas, kondisi kerikil sudah } \\
\text { berlumut, kurang terawat }\end{array}$ & 1 \\
\hline Tempat duduk & Disediakan untuk pengunjung wisata & $\begin{array}{l}\text { Kurang terawat dan kurangnya } \\
\text { ketersediaan tempat duduk }\end{array}$ & 25 \\
\hline Warung & Menyediakan makanan dan minuman & Kondisi kurang tertata & 5 \\
\hline Toilet & $\begin{array}{l}\text { Tempat ruang ganti, ruang bilas, dan } \\
\text { buang air besar dan kecil. }\end{array}$ & $\begin{array}{l}\text { Kurang terawat, tidak ada air bersih } \\
\text { untuk pengguna toilet. }\end{array}$ & 2 \\
\hline $\begin{array}{l}\text { Tempat } \\
\text { sampah }\end{array}$ & $\begin{array}{l}\text { Tempat pembuangan sampah agar } \\
\text { lingkungan tetap bersih. }\end{array}$ & Minimnya ketersediaan tempat sampah. & 4 \\
\hline
\end{tabular}

Berikut peta tata letak fasilitas tersedia yang terdapat di jalur wisata yang terdiri dari jalur permukiman, jalur utama wisata dan jalur alternatif, yang terlihat pada Gambar 4, 5, dan 6 .

3.2.4 Aspek Sosial, Ekonomi dan Budaya

Gunung Padang termasuk dalam kelurahan Batang Arau, kecamatan Padang selatan RT.004/ RW.005 yang terdapat sekitar 20 kepala keluarga, masyarakat menilai wisata Gunung Padang ini dapat berpotensi dalam aspek perekonomian. Berdasarkan data pengunjung tahun 2014 sampai 2018 terdapat bahwa jumlah wisatawan yang berkunjung mengalami kondisi grafik yang atau fluktuatif. Dari data yang telah diperoleh di lokasi penelitian ada beberapa aktivitas yang dilakukan pengunjung di kawasan wisata Gunung Padang ini antara lain sebagai berikut yaitu memancing, panjat tebing, menikmati pemandangan, piknik, hiking, dan kegiatan sosial.

\subsection{Analisis dan Sintesis}

\subsubsection{Aspek Biofisik}

Gunung Padang didominasi oleh tanah entisols, pada umumnya terdapat pada lereng bagian atas perbukitan. Tanah entisol merupakan tanah yang masih sangat muda, yaitu baru dalam proses tingkat permulaan dalam perkembangannya. Pengelolaan lahan dilakukan dengan cara memperbanyak tanaman penutup tanah seperti rumput atau alang-alang, pembuatan terasering pada lereng miring agar tidak mudah tererosi, membiarkan tanaman yang sudah tumbuh alami atau melakukan penanaman pohon-pohon untuk jadi hutan lindung, melakukan rotasi tanaman untuk menjaga ketersediaan unsur hara (Hermon, 2005).

Gunung Padang termasuk dalam kawasan konservasi di Kota Padang, karena mempunyai vegetasi dan satwa serta ekosistemnya yang harus dilindungi dan dilestarikan keberadaannya. Bentuk dari vegetasi pada tapak penelitian yaitu terdapat rumpun tanaman yang terdiri dari penutup tanah, semak belukar dan pohon penaung yang tersebar di kawasan penelitian. 


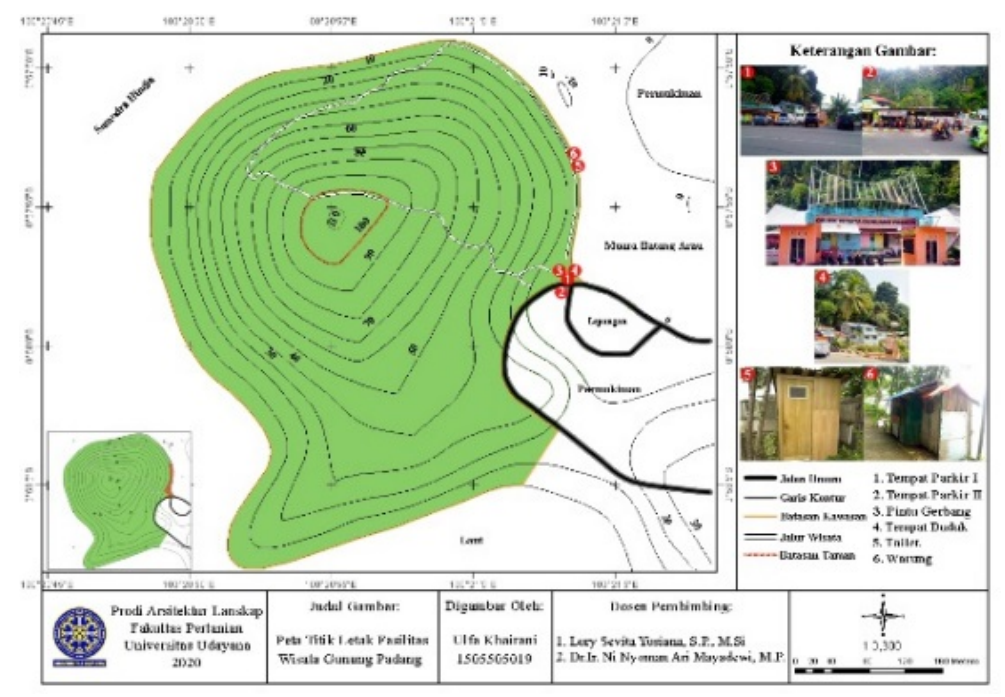

Gambar 4. Peta Letak Fasilitas di Jalur Permukiman

(Sumber: Pengolahan Data, 2020)

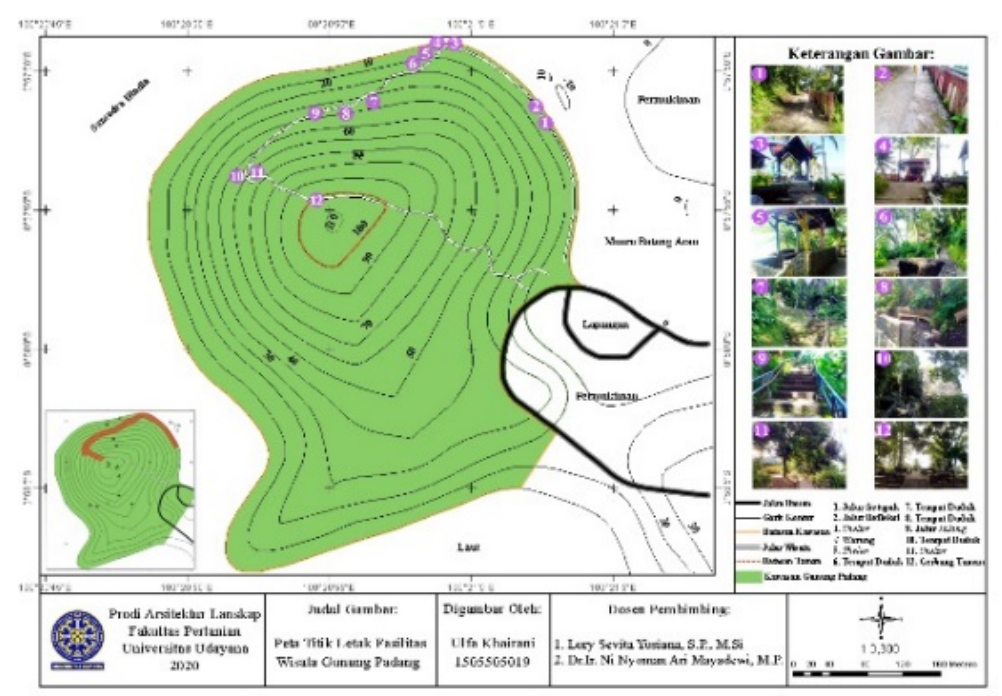

Gambar 5. Peta Letak Fasilitas di Jalur Utama Wisata (Sumber: Pengolahan Data, 2020)

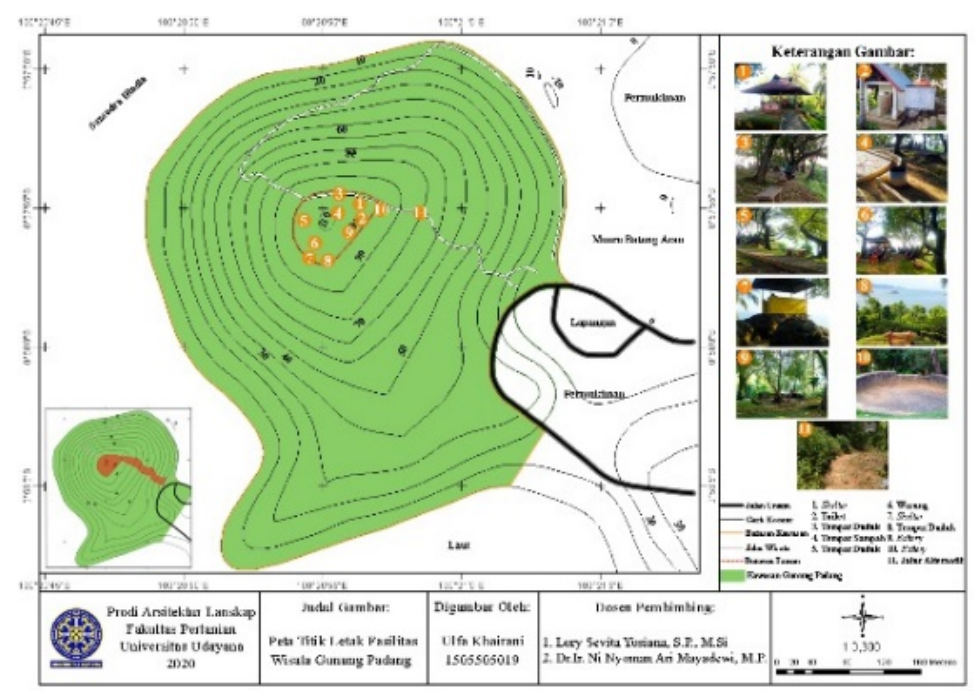

Gambar 6. Peta Letak Fasilitas di Taman Siti Nurbaya dan Jalur Alternatif (Sumber: Pengolahan Data, 2020) 


\subsubsection{Potensi Wisata Gunung Padang}

Kondisi potensi wisata ini terdapat masih asri keindahan alamnya serta bangunan yang terdapat di tapak, namun ada beberapa bangunan yang kurang dilestarikan dan dirawat keberadaannya. Sehingga dari beberapa bangunan seperti benteng bunker, lobang Jepang beberapa keberadaan bangunannya sudah hilang atau tertimbun oleh tanah dan tumbuh-tumbuhan yang hidup di kawasan tersebut. Karena lokasi tapak ini adalah kawasan wisata maka sebaiknya perlu adanya kesadaran dalam memperhatikan kondisi kawasan wisata, dengan melakukan tindakan untuk merawat dan melestarikan potensi yang ada di tapak dalam meningkatkan dan mengembangkan wisata, sehingga potensi-potensi tersebut dapat lebih terjaga dan tetap menjadi penarik wisatawan untuk berkunjung dengan menikmatinya.

\subsubsection{Fasilitas Wisata}

Fasilitas wisata yang tersedia di kawasan wisata keberadaannya masih sangat minim dengan kondisi fisik yang kurang baik. Hal ini menjadi penyebab kendala dalam pengelolaan wisata, karena kurangnya kesadaran dan perhatian terhadap kondisi wisata. Fasilitas tersedia yang terdapat di kawasan wisata masih dinilai kurang memberikan keamanan dan kenyamanan kepada pengunjung wisata. Untuk itu fasilitas yang ada di kawasan ini perlu dirawat, dijaga, diperbaiki dan ditambahkan ketersediaannya sesuai dengan kebutuhan yang memberikan pelayanan dan kemudahan dalam melakukan kegiatan wisata.

Ditemukan salah satu fasilitas dengan kondisi yang disalahgunakan oleh masyarakat sekitar, fasilitas tersebut berupa shelter. Shelter ini jarang di tempati oleh pengunjung karena tidak memiliki tempat duduk yang layak untuk pengunjung, sehingga masyarakat sekitar memanfaatkan fasilitas tersebut sebagai tempat berjualannya. Hal ini memerlukan penyelesaian masalah agar shelter dapat berfungsi dengan baik, menambahkan fasilitas tempat duduk serta aman dan nyaman digunakan oleh pengunjung. Warung yang terdapat di lokasi tersebut dipindahkan sesuai dengan tata letaknya, karena dapat mengurangi nilai estetika kawasan.

Setelah menganalisis fasilitas wisata yang tersedia dan fasilitas yang disalahgunakan selanjutnya dilakukan analisis terhadap fasilitas yang belum tersedia di kawasan wisata, seperti papan interpretasi, papan petunjuk arah, spot foto, pagar untuk keamanan pengunjung di taman Siti Nurbaya dan juga fasilitas Fasilitas tersebut dibutuhkan oleh pengunjung untuk mempermudah dalam melakukan kegiatan wisata, serta memberikan keamanan dan kenyamanan bagi pengunjung. Oleh karena itu, diberikan rekomendasi yang berupa gambar-gambar ilustrasi sesuai kebutuhan pengunjung untuk pengembangan wisata fasilitas wisata, terlihat pada Gambar 7.

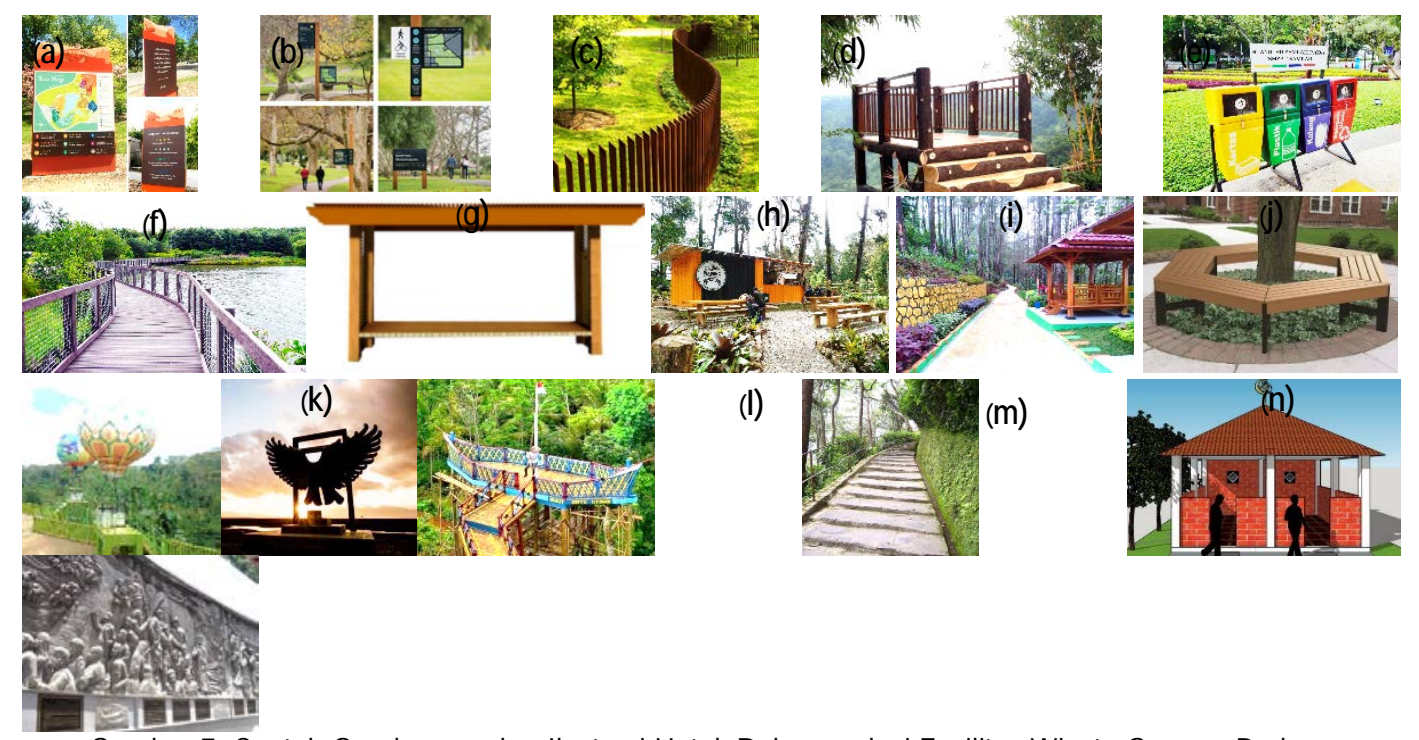

Gambar 7. Contoh Gambar-gambar Ilustrasi Untuk Rekomendasi Fasilitas Wisata Gunung Padang

(a) Papan interpretasi, (b) Papan Petunjuk arah, (c) Pagar, (d) Platform pengamat, (e) Tempat sampah

(f) Boardwalk, (g) Shelter, (h) Kafe, (i) Jalur pejalan kaki, (j) Tempat duduk, (k) Spot foto, (l) Jalur hiking,

\subsubsection{Aspek Sosial, Ekonomi dan Budaya} (m) Musala, (n) Relief. 
Dinas Pariwisata dan Kebudayaan kota Padang dalam mengembangkan kawasan wisata Gunung Padang mengalami kendala dan hambatan yang berupa dari sisi anggaran, karena anggaran merupakan faktor utama yang diperlukan untuk mengembangkan kawasan wisata, kurangnya kesadaran masyarakat akan peran dan tanggung jawabnya sebagai tuan rumah pariwisata dan juga kurangnya pengkoordinasiannya dari Dinas Pariwisata dan Kebudayaan Kota Padang. Oleh karena itu Dinas Pariwisata dan Kebudayaan Kota Padang seharusnya lebih giat dalam melakukan kerjasama dengan pihak swasta, organisasi pemerintahan, dan masyarakat agar pengembangan kawasan wisata Gunung Padang bisa berjalan dengan baik.

\subsection{Konsep}

Konsep dasar dari penelitian ini adalah optimalisasi potensi lanskap guna mendukung pengembangan wisata di Gunung Padang, Kota Padang. Optimalisasi dilakukan terhadap wisata yang ada yaitu atraksi wisata, aktivitas wisata, dan fasilitas wisata sebagai penunjang wisata utama. Berdasarkan konsep dasar yang telah ditentukan maka konsep pengembangan perencanaan lanskap untuk pengembangan wisata bertujuan untuk merekomendasi sarana dan prasarana penunjang kegiatan wisata, yang memberikan keamanan dan kenyamanan bagi pengunjung wisata. Konsep pengembangan ini meliputi konsep ruang, konsep sirkulasi, konsep 4A, dan konsep tata hijau.

Ruang dikelompokan menurut fungsinya sehingga terbentuk ruang pemanfaatan dalam kegiatan berwisata yang terbagi menjadi beberapa zona berdasarkan jalur wisata yaitu, zona 1 terdapat pada jalur permukiman yang memiliki sub ruang yaitu ruang penerimaan, zona 2 terdapat pada jalur utama wisata terbagi menjadi sub ruang sejarah, ruang pelayanan dan ruang rekreasi, sedangkan zona 3 terdapat pada jalur alternatif yaitu ruang konservasi.

Jalur sirkulasi ini dapat menghubungkan antara daya tarik wisata dan atraksi wisata dengan adanya fasilitas pendukung yang membantu mempermudah pengunjung dalam berwisata. Disamping itu, dapat dilalui pejalan kaki dengan adanya pembatasan jumlah pengunjung sesuai dengan daya dukungnya. Jalur ini dilengkapi dengan fasilitas papan interpretasi dan papan petunjuk arah.

Daya tarik wisata menurut Cooper (1995 dalam Setiawan, 2015) mengemukakan bahwa terdapat empat komponen yang harus dimiliki oleh sebuah daya tarik wisata, yaitu attraction, accessibility, amenity, dan ancillary.

1. Attraction (Atraksi)

Secara umum, atraksi dapat dibedakan ke dalam tiga jenis yaitu atraksi buatan alam seperti bukit, hutan lindung, pemandangan alam sekitar Gunung Padang, atraksi sejarah dan budaya terdapat seperti bangunan peninggalan bersejarah, dan makam Siti Nurbaya, sedangkan atraksi buatan manusia berupa taman Siti Nurbaya, tagline, dan boardwalk.

\section{Accessibility (Aksesibilitas)}

Faktor-faktor yang penting dapat ditingkatkan dalam pengembangan wisata Gunung Padang, terdapat penyediaan informasi terkait wisata yang berupa petunjuk arah, waktu yang dibutuhkan, biaya perjalanan, dan frekuensi transportasi menuju lokasi wisata.

\section{Amenity (Fasilitas)}

Fasilitas yang direncanakan di wisata Gunung Padang adalah fasilitas yang mendukung aktivitas wisata yang mampu menunjang kegiatan wisata serta memberikan pelayanan dan kenyamanan kepada pengunjung. Fasilitas tersebut berupa papan interpretasi, papan petunjuk arah, counter ATM, tempat sampah, tempat duduk, shelter, platform pengamat, musala, relief, dan spot foto. Konsep fasilitas wisata memiliki nilai kebudayaan setempat, hal ini bertujuan untuk memberi nilai identitas bagi kawasan dan mampu menjadikan kawasan wisata Gunung Padang sebagai salah satu ikon Kota Padang dengan pelestarian budaya, sejarah dan lingkungan alamnya.

4. Ancillary (Pelayanan Tambahan)

Organisasi yang memfasilitasi dan mendorong pengembangan serta pemasaran dari suatu destinasi wisata yaitu Dinas Pariwisata dan Kebudayaan serta masyarakat sekitar yang bertanggung jawab untuk mendukung pengembangan wisata.

Konsep tata hijau pada tapak ini berfungsi sebagai kawasan konservasi dengan melindungi dan melestarikan ekosistem vegetasi dan satwa yang terdapat di kawasan wisata Gunung Padang dengan 
mempertahankan vegetasi yang ada saat ini dan meminimalisasi penghilangan dan pemangkasan vegetasi pada saat penempatan fasilitas wisata.

\subsection{Perencanaan}

Sesuai dengan konsep untuk pengembangan kawasan wisata maka rencana tata ruang dibagi menjadi lima ruang yaitu ruang penerimaan, ruang pelayanan, ruang sejarah, ruang rekreasi, dan ruang konservasi yang sesuai dengan pengembangan atraksi wisata, aktivitas wisata dan fasilitas wisata (Tabel 2).

Tabel 2. Rencana Tata Ruang Wisata Gunung Padang.

\begin{tabular}{|c|c|c|c|}
\hline Ruang & Atraksi & Aktivitas & Fasilitas \\
\hline \multicolumn{4}{|l|}{ Zona 1} \\
\hline Ruang penerimaan & & $\begin{array}{l}\text { Pembelian tiket, Penerimaan } \\
\text { informasi, Persiapan memasuki } \\
\text { kawasan wisata, Keluar masuk }\end{array}$ & $\begin{array}{l}\text { Pintu gerbang, Loket tiket, Panel } \\
\text { interpretasi kawasan wisata, Pos } \\
\text { keamanan, parkir, Spot foto, } \\
\text { Tempat sampah, Counter ATM. }\end{array}$ \\
\hline \multicolumn{4}{|r|}{ 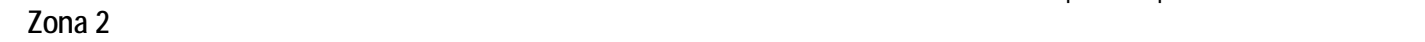 } \\
\hline Ruang layanan & $\begin{array}{l}\text { Bukit Panorama, } \\
\text { Tebing }\end{array}$ & $\begin{array}{l}\text { Istirahat, Makan dan minum, } \\
\text { Menikmati pemandangan, Photo } \\
\text { hunting, Panjat tebing, Pengenalan } \\
\text { keragaman satwa dan vegetasi }\end{array}$ & $\begin{array}{l}\text { Shelter, Tempat duduk, Toilet, } \\
\text { Tempat sampah, Papan } \\
\text { interpretasi, Papan petunjuk arah, } \\
\text { Boardwalk }\end{array}$ \\
\hline \multicolumn{4}{|c|}{ 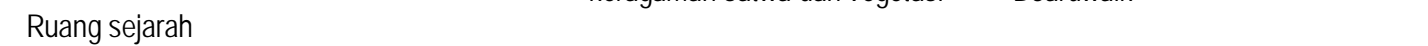 } \\
\hline a) Makam & Makam Siti Nurbaya & Pengenalan wisata sejarah & Papan interpretasi \\
\hline $\begin{array}{l}\text { b) Bangunan } \\
\text { Peninggalan Jepang }\end{array}$ & $\begin{array}{l}\text { Bunker, Meriam, } \\
\text { Battery, Relief }\end{array}$ & Pengenalan Wisata Sejarah & Papan interpretasi \\
\hline Ruang Rekreasi & Taman Siti Nurbaya & $\begin{array}{l}\text { Piknik, Camping, Photo hunting, } \\
\text { Istirahat, } \\
\text { pemandangan }\end{array}$ & $\begin{array}{l}\text { Shelter, Menara pengamat, } \\
\text { Warung, Toilet, Tempat duduk, } \\
\text { Tempat sampah, Spot foto, } \\
\text { Mushola, Papan petunjuk arah, } \\
\text { Papan interpretasi }\end{array}$ \\
\hline \multicolumn{4}{|l|}{ Zona 3} \\
\hline Ruang Konservasi & Tagline Kota Padang & $\begin{array}{l}\text { Pengelolaan kawasan dan } \\
\text { Melestarikan kawasan }\end{array}$ & $\begin{array}{l}\text { Jalur pejalan kaki, Papan petunjuk } \\
\text { arah, Tempat Sampah }\end{array}$ \\
\hline
\end{tabular}

Jalur sirkulasi pada tapak ini terbagi atas dua, yaitu jalur sirkulasi primer dan jalur sirkulasi sekunder. Jalur sirkulasi primer merupakan jalur umum yang dapat dilalui kendaraan dengan bebas secara dua arah, sedangkan sirkulasi sekunder yaitu penghubung antara ruang pada tapak terlihat pada Gambar 8.

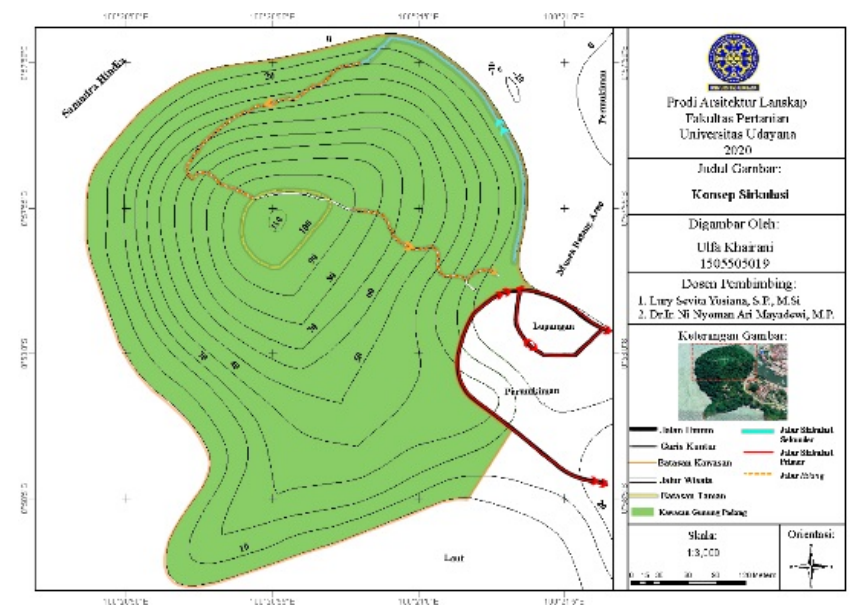

Gambar 8. Gambar Rencana Sirkulasi Tapak

\subsubsection{Rencana 4A}

1. Attraction (Atraksi) 
Atraksi wisata berkaitan dengan aktivitas wisata yang dapat dikembangkan pada kawasan wisata bersifat rekreatif dan edukatif. Selain itu pengunjung dapat pengetahuan tentang kawasan konservasi, peninggalan sejarah dan budaya yang ada pada kawasan wisata tersebut serta menikmati pelayanan yang telah disediakan oleh pengelola. Berikut ini adalah gambaran rencana aktivitas yang dapat dikembangkan pada tapak sesuai dengan pembagian ruang dan konsepnya, terlihat pada Gambar 9.

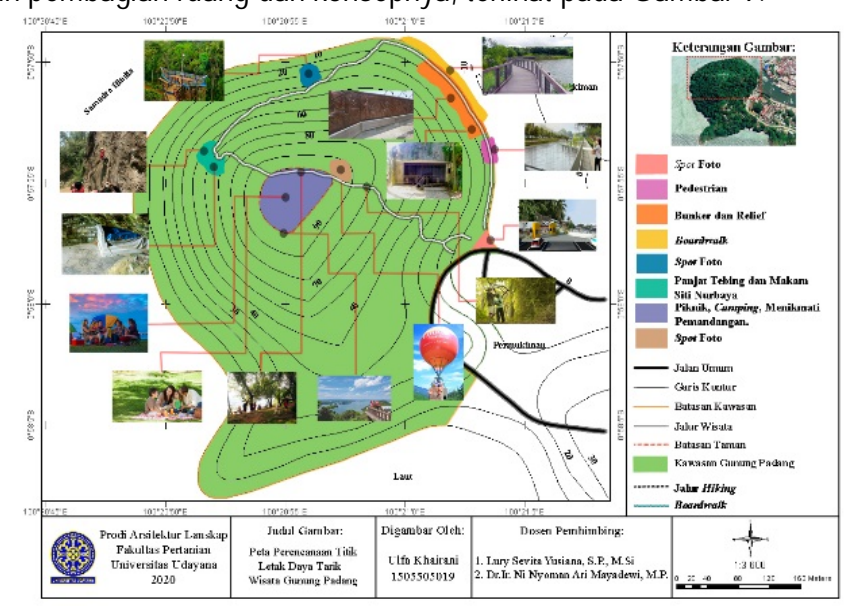

Gambar 9. Peta Rencana Atraksi dan Aktivitas Wisata di Gunung Padang

\section{Accessibility (Aksesibilitas)}

Aksesibilitas untuk menuju kawasan wisata Gunung Padang terdapat jalan utama yang bernama jalan Kampung Batu dengan kondisi baik. Jalan ini memiliki jalur dua arah yang berlawanan, namun perlu ditambahkan papan petunjuk arah dan papan informasi mengenai lokasi wisata tersebut. Untuk transportasi yang bisa di akses menuju kawasan wisata tersebut, bisa menggunakan kendaraan pribadi berupa motor dan mobil. Sedangkan untuk kendaraan umum saat ini sudah tidak berfungsi lagi, biasanya terdapat mobil umum (angkot) dan becak motor (bentor).

3. Amenity (Fasilitas)

Penempatan fasilitas sesuai dengan kebutuhan tiap ruang-ruang wisata dengan tetap memperhatikan fungsi perlindungan dan pelestarian keanekaragaman hayati Gunung Padang. Hal ini dilakukan agar fasilitas lebih mudah dicapai oleh pengunjung dan memberikan pelayanan yang aman untuk menunjang kegiatan wisata. Fungsi ruang disesuaikan dengan atraksi, aktivitas dan fasilitas wisata (Gambar 10).

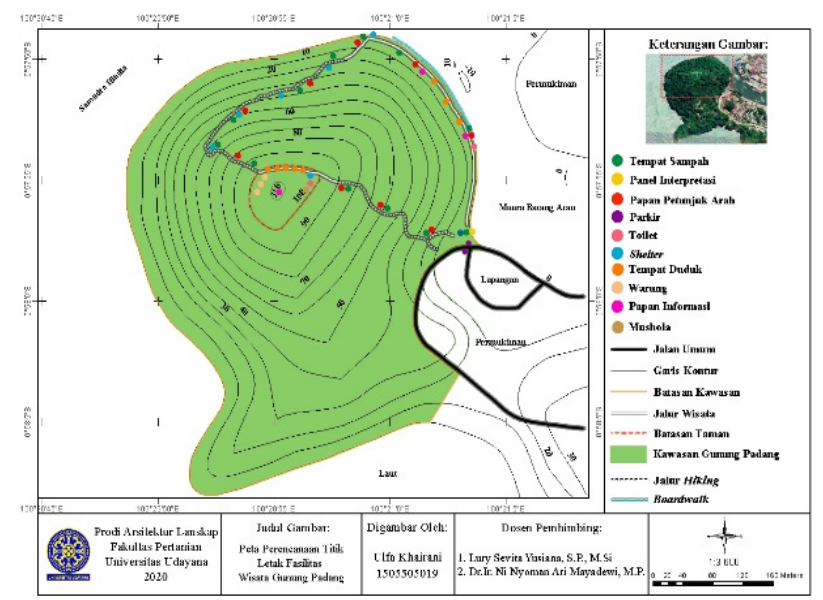

Gambar 10. Peta Perencanaan Tata Letak Fasilitas Wisata di Gunung Padang

4. Ancillary (Pelayanan Tambahan)

Diharapkan Dinas Pariwisata dan Kebudayaan Kota Padang lebih optimal dan maksimal dalam melakukan perannya sebagai fasilitator, dinamisator dan motivator. Selain itu Dinas Pariwisata dan 
Kebudayaan Kota Padang juga dituntut untuk lebih agresif dalam mempromosikan kawasan wisata Gunung Padang agar lebih dikenal oleh masyarakat lokal maupun mancanegara. Masyarakat yang berperan dan bertanggung jawab atas pengelolaan kawasan wisata wajib mengikuti pembinaan dan sosialisasi yang diadakan oleh Dinas Pariwisata dan Kebudayaan Kota Padang terkait kawasan wisata. (Hasanah, 2019)

Tata hijau pada kawasan wisata Gunung Padang adalah menjaga dan melestarikan kawasan hutan lindung atau kawasan konservasi serta ekosistem yang bertahan hidup di kawasan tersebut. Menambahkan atraksi atau aktivitas wisata terkait penggunaan hutan yang ada di tapak berupa pengamatan vegetasi dan satwa yang tumbuh dengan baik di kawasan tersebut dan juga menambah beberapa papan interpretasi pada zona konservasi.

\section{Penutup \\ 4.1 Simpulan}

Konsep dasar dari penelitian ini adalah menyusun perencanaan lanskap guna mendukung pengembangan wisata dimulai dari berbagai potensi wisata yang dimiliki yaitu atraksi wisata, aktivitas wisata, dan fasilitas wisata yang menjadi penunjang dalam kegiatan wisata. Konsep pengembangan terdiri dari konsep ruang, konsep sirkulasi, konsep 4A dan konsep tata hijau. Selanjutnya, rencana tata ruang dibagi menjadi lima ruang yaitu ruang penerimaan, ruang pelayanan, ruang sejarah, ruang rekreasi, dan ruang konservasi. Setiap ruang dibagi menjadi beberapa fungsi ruang yang disesuaikan dengan atraksi wisata, aktivitas wisata dan fasilitas wisata agar sesuai dengan kebutuhan wisatawan.

Rencana sirkulasi terdiri dari jalur sirkulasi primer dan sekunder, sedangkan rencana berdasarkan 4A terdiri dari attraction (atraksi), meliputi bukit Gunung Padang, lanskap kawasan sekitar Gunung Padang, peninggalan sejarah dan budaya, dan taman Siti Nurbaya, accessibility (aksesibilitas) meliputi jalan menuju kawasan wisata yang dilengkapi oleh sarana dan prasarana terkait informasi wisata, amenity (fasilitas) meliputi memberi rekomendasi terkait sarana dan prasarana wisata guna menunjang pengembangan wisata, dan ancillary (pelayanan tambahan) meliputi mengoptimalkan dan memaksimalkan peningkatan pengembangan wisata. Rencana tata hijau disusun untuk mendukung pelestarian kawasan hutan lindung atau kawasan konservasi serta ekosistem yang ada di kawasan ini.

\subsection{Saran}

Perencanaan lanskap untuk pengembangan wisata di Gunung Padang ini masih memerlukan penelitian lanjutan yang berfokus pada habitat satwa endemik di Gunung Padang, seperti pada beberapa spesies monyet yang ada agar populasinya tidak punah dan meningkatkan atraksi wisata dari satwa tersebut. Kekurangan dari penelitian ini adalah belum terpenuhinya aspek pendukung untuk penataan area parkir yang saat ini belum mampu memfasilitasi kebutuhan pengunjung di Gunung Padang. Oleh karena itu, diharapkan agar penelitian selanjutnya, dapat dilakukan untuk meningkatkan kenyamanan wisata Gunung Padang.

\section{Daftar Pustaka}

Emmanuel, R. (2005). Thermal comfort implications of urbanization in a warm-humid city: The Colombo Metropolitan Region (CMR), Sri Lanka. Building and Environment, 40(12), 1591-1601. https://doi.org/10.1016/j.buildenv.2004.12.004

Hasanah, N. (2019). Peran Dinas Pariwisata dan Kebudayaan Kota Padang Dalam Pengembangan Kawasan Wisata Gunung Padang. 3(20), 109-115.

Hermon, D. (2005). Analisis Spatial Bahaya Dan Risiko Longsor Lahan Di Gunung Padang Sumatera Barat.

Indonesia, U.-U. R. (2009). Undang-Undang Republik Indonesia Nomor 10.Tahun 2009 Tentang Kepariwisataan.

Istiningrum, D. T., S, R. L. A. W., Mukhlisin, M., Rochadi, M. T., Teknik, J., Politeknik, S., \& Semarang, N. (2010). Kajian Kenyaman Termal Ruang Kuliah Pada Gedung Sekolah C Lantai 2 Politeknik Negeri Semarang. 1-16.

Lerissa. (2014). Perencanaan Jalur Interpretasi Di Kawasan Wisata Gunung Padang Sumatera Barat.

Purwantara, S. (2018). Studi Temperatur Udara Terkini Di Wilayah Di Jawa Tengah Dan Diy. Geomedia: Majalah Ilmiah Dan Informasi Kegeografian, 13(1), 41-52. https://doi.org/10.21831/gm.v13i1.4476

Setiawan, I. (2015). Identifikasi Potensi Wisata Beserta 4a (Attraction, Amenity, Accessibility, Ancillary) Di Dusun Sumber Wangi, Desa Pemuteran, Kecamatan Gerokgak, Kabupaten Buleleng, Bali Nama. Retrievedfromhttps://repositori.unud.ac.id/protected/storage/upload/penelitianSimdos/ł3e2c92782684 ae4ee371072d490ae74.pdf\%0D 